\title{
Synthesis of Thermally Stable Reactive Polyurethane and Its Physical Effects in Epoxy Composites
}

\author{
Jin Hong Kim ${ }^{1,2}$, Wonjoo Lee ${ }^{1}$, Taehee Kim ${ }^{1}$, Hyeon-Gook Kim ${ }^{1}$, Bongkuk Seo ${ }^{1}$, \\ Choong-Sun Lim ${ }^{1, *}$ and In Woo Cheong ${ }^{2, *}$ (i) \\ 1 Center for Chemical Industry Development, Korea Research Institute of Chemical Technology, 45, Jongga-ro, \\ Yugok-dong, Jung-gu, Ulsan 44412, Korea; style6889@naver.com (J.H.K.); winston@krict.re.kr (W.L.); \\ kimth@krict.re.kr (T.K.); candoit@krict.re.kr (H.-G.K.); bksea@krict.re.kr (B.S.) \\ 2 School of Applied Chemical Engineering, Kyungpook National University, Daegu 41566, Korea \\ * Correspondence: chsunlim@krict.re.kr (C.-S.L.); inwoocheong@gmail.com (I.W.C.); \\ Tel.: +82-52-241-6021 (C.S.L.); Fax: +82-52-241-6029 (C.S.L.)
}

Received: 19 July 2018; Accepted: 5 September 2018; Published: 7 September 2018

\begin{abstract}
A flame retardant polyol (EP-DOPO) with epoxy functional groups was synthesized by reacting a 1,6-hexanediol glycidyl ether with a flame retardant 10-(2,5-dihydroxyphenyl)10H-9-oxa-10-phospha-phenanthrene-10-oxide (DOPO). The polyurethane (EPPU) with enhanced heat resistance was prepared by the reaction of a polyol blend of EP-DOPO and polytetrahydrofuran (PolyTHF) at a ratio of 1:1 with isophorone diisocyanate. EPPU useful for the preparation of cables or coatings showed higher thermal decomposition temperature rather than that of reference polyurethane synthesized by the reaction between pure PolyTHF and isophorone diisocyanate by thermogravimetric analysis. Further study of the polyurethane as a toughening agent for epoxy polymers was carried out. Epoxy compositions consisting of bisphenol A epoxy resin and dicyandiamide as a hardener have a brittle property allowing crack propagation after cure. Polyurethane plays an important role as an impact modifier to prevent from cracks of epoxy polymers. Various contents of EPPU were added into epoxy compositions to measure the physical property changes of epoxy polymers. The tensile and flexural strengths of the cured specimen were compared with those of epoxy compositions including reference polyurethane. Furthermore, the crosslink density of the cured epoxy compositions was compared.
\end{abstract}

Keywords: polyurethane; flame retardant; epoxy; crosslink density; impact resistance

\section{Introduction}

Polyurethanes (PUs) are polymers composed of a soft segment and a hard segment prepared by the reaction between hard isocyanates and soft polyols. Polypeptides of the hard segments form strong hydrogen interactions with each other. In contrast, soft segments comprising linear long-chain polyols have flexible properties. The physical properties of synthesized polyurethanes depend on the reaction ratio between isocyanate and polyol and the types of reactants, such as polyols, chain extenders, or isocyanates. Therefore, a variety of synthetic polyurethanes prepared with various combinations of reactants have been widely adopted in automotive interior materials, adhesives, coatings, shoes, clothing, etc.

However, the low thermal stabilities of polyurethanes limit their use in high-temperature processes or applications. Furthermore, polyurethanes begin to decompose at temperatures $>180^{\circ} \mathrm{C}$, resulting in the production of toxic gases, such as $\mathrm{HCN}$ or $\mathrm{CO}$, that are harmful to the human body or environment [1-4].

Recently, researchers have been interested in introducing flame retardants into polyurethanes to compensate for the low thermal stability. The flame retardants can be classified into two types: 
an additive type, in which a flame retardant is physically added to the polymeric resin, and a reactive type, in which a flame retardant reacts with reactant monomers, forming polymers. In general, the most often used additive flame retardants need to be highly miscible with the raw materials and not deteriorate the mechanical properties of the produced polymers nor produce any toxic gases.

Since environmental regulations prohibit the use of halogenated flame retardants, phosphoric flame retardants have attracted attention as one alternative. In particular, the flame retardancy of polyurethane is improved by introducing a monomer having flame retardancy into the main chain, using a method of encapsulating the flame retardant at the end of the polyurethane or by using organic-inorganic additives [5-8].

Epoxy resins are thermosetting polymers constructed of three-dimensional network structures after a curing reaction with hardeners in the presence of catalysts. Epoxy resin derivatives can exhibit various physical properties by reacting with different hardeners, and they are widely used in coatings, adhesives, and moldings because the polymerized matrices provide excellent thermal and mechanical properties and chemical resistance $[9,10]$. However, the high brittleness of cured epoxy polymers promotes easy crack propagation. Therefore, numerous scientists have reported methods to reduce this brittleness by adding thermoplastic resin, rubber resins, or elastomeric polyurethanes $[11,12]$. Specifically, polyurethanes in epoxy compositions, which are known to be phase separated after curing, have been added to absorb external impact $[13,14]$.

In this report, a phosphoric monomer was reacted with an epoxy resin to prepare a reactive polyol. The polyol mixed with a polyether polyol in a 1:1 ratio was reacted with 2 mol of isophorone diisocyanate to enhance thermal resistance. In addition, the prepared polyurethane was added to epoxy compositions to investigate physical changes, where bisphenol A epoxy resin and dicyandiamide (dicy) were stoichiometrically blended. The effects of the prepared polyurethane addition to the epoxy compositions were further analyzed with tensile and flexural strength measurements, the Izod impact method, thermogravimetric analysis, and scanning electron microscopy.

\section{Materials and Methods}

\subsection{Materials}

The phosphorous flame retardant 10-(2,5-dihydroxyphenyl)-10H-9-oxa-10-phospha-phenanthrene10-oxide (DOPO) was obtained from Pharmicell Co., Ltd. (Ulsan, Korea) and 1,6-Hexanediol glycidyl ether (HDGE) was purchased from HJ Chemco (Ulsan, Korea). Tetrabutylammonium iodide (TBAI), polytetrahydrofuran (PolyTHF) $\left(M_{n}=2000 \mathrm{~g} / \mathrm{mol}\right)$, isophorone diisocyanate (IPDI), and 2-allyl phenol (2-AP, 98\%) were purchased from Sigma-Aldrich (St. Louis, MO, USA). Dibutyltindilaurylmercaptide (DBTDL) was obtained from Gelest Co (Morrisville, PA, USA). Bisphenol A epoxy resin (DGEBA, $187 \mathrm{~g} / \mathrm{eq}$ ) was purchased from Momentive Co (USA). The hardener, dicyandiamide, and 1,1-dimethyl-3-phenyl urea (DPU) were obtained from Air Products (Arlington, PA, USA).

\subsection{Preparation of Polyol (EP-DOPO)}

DOPO $(64.8 \mathrm{~g})$ and HDGE $(92 \mathrm{~g})$ were poured into a $500 \mathrm{~mL}$ beaker and stirred at $60^{\circ} \mathrm{C}$ until the DOPO completely dissolved. TBAI, a catalyst, was added to the beaker, which was heated at $150{ }^{\circ} \mathrm{C}$ for $1 \mathrm{~h}$ (Figure 1). The product was cooled to room temperature and characterized (Figure 2). 

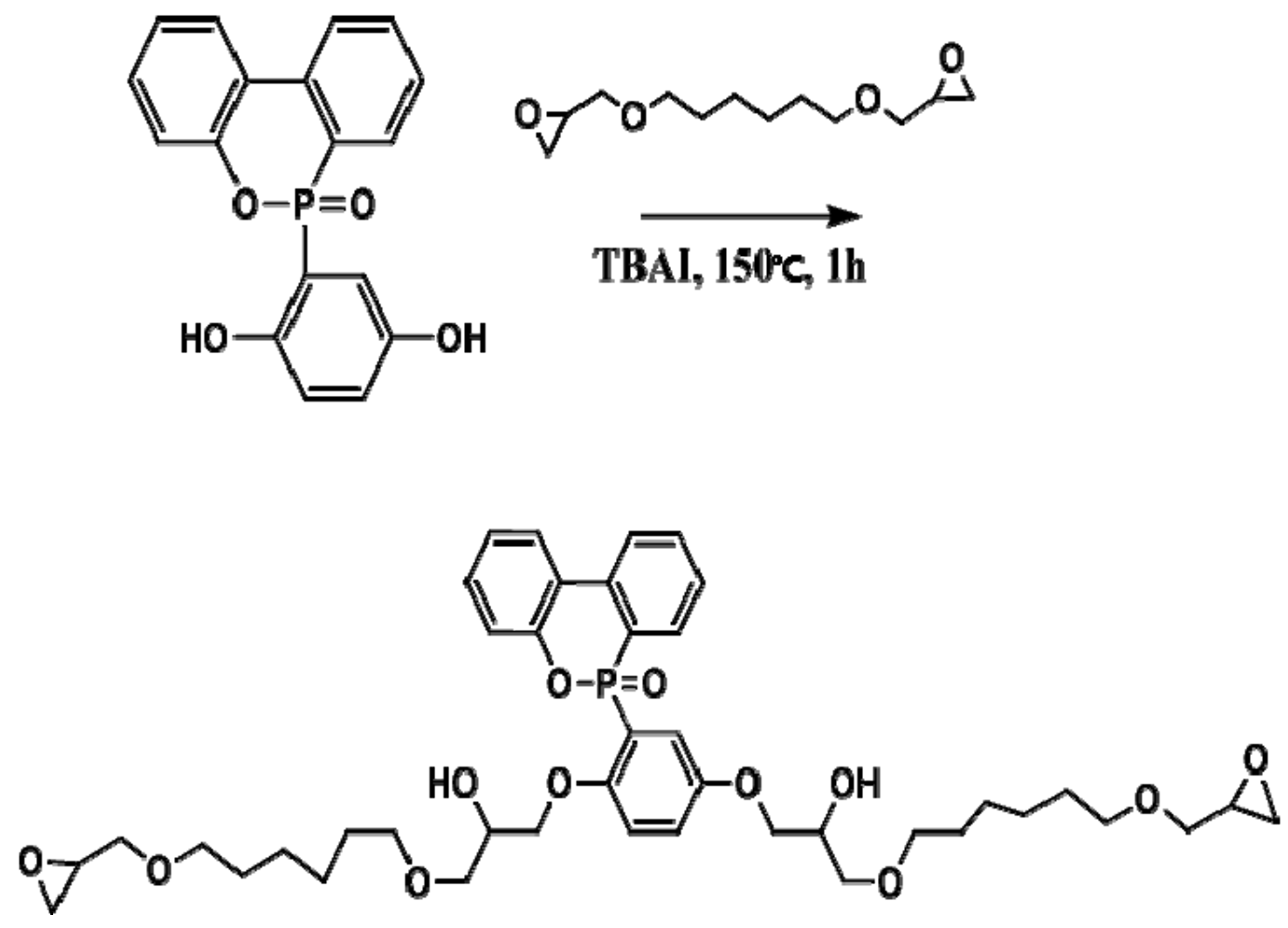

Figure 1. Preparation of polyol (EP-DOPO) reaction scheme.

\subsection{Synthesis of Polyurethane}

Reference polyurethane (Ref PU) was prepared by reacting PolyTHF ( $80 \mathrm{~g}, 0.04 \mathrm{~mol}$ ) with IPDI $\left(34 \mathrm{~mL}, 0.08 \mathrm{~mol}\right.$ ) at $90^{\circ} \mathrm{C}$ for $90 \mathrm{~min}$ under nitrogen in the presence of DBTDL catalyst. Then, 2-AP

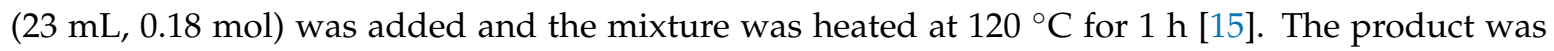
cooled to room temperature. Modified polyurethane (EPPU) was prepared by reacting IPDI $(34 \mathrm{~mL}$, $0.08 \mathrm{~mol})$ with the mixture of PolyTHF $(40 \mathrm{~g}, 0.02 \mathrm{~mol})$ and EP-DOPO $(15.6 \mathrm{~g}, 0.02 \mathrm{~mol})$ at $90^{\circ} \mathrm{C}$ for $2.5 \mathrm{~h}$ under nitrogen. After the addition of 2 -AP $(26 \mathrm{~mL}, 0.2 \mathrm{~mol})$, the solution was stirred at $120^{\circ} \mathrm{C}$ for $1 \mathrm{~h}$. Two types of flame retardant polyurethanes (EPPU, and EPPU-2) were synthesized based on the molar ratio of PTMG, EP-DOPO, and IPDI. EPPU had a molar ratio of 0.2:0.2:0.8, while EPPU-2 had a ratio of 0:0.4:0.8, as shown in Figure 3.

\subsection{Preparation of Epoxy Compositions and Curing Process}

DGEBA and dicy (1:1 mole ratio) with DPU $(0.2 \%)$ were stirred with a mechanical stirrer at 80 ${ }^{\circ} \mathrm{C}$ under vacuum for $30 \mathrm{~min}$. Elastic polyurethanes were added to the epoxy binder in the range of 10 to 30 parts per hundred resin (phr) to provide a toughening effect to the cured epoxy compositions. The resin composition was poured into a metal mold, followed by heating at $150^{\circ} \mathrm{C}$ for $1 \mathrm{~h}, 170{ }^{\circ} \mathrm{C}$ for $1 \mathrm{~h}$, and $190^{\circ} \mathrm{C}$ for $1 \mathrm{~h}$ to complete the curing.

\subsection{Characterization and Analysis}

Elemental analysis was performed with an elemental analyzer (EA, Flash 2000, Thermo Fisher, Basingstok, UK). The molecular weight of the synthesized polyol was measured using liquid chromatography-mass spectrometry (LC-MS, G6130, Agilent Technologies, New York, NY, USA), while the structure was analyzed using Fourier-transform nuclear magnetic resonance (FT-NMR, Avance 3300, Bruker, Karlsruhe, Germany). The LC-MS system ionized the sample using electron spray ionization (ESI), and the eluent had a 1:1 ratio of acetonitrile:dried water (formic acid $0.2 \%$ ) under a $0.7 \mathrm{~mL} / \mathrm{min}$ flow rate. The molecular weight of the synthesized polyurethane was measured using gel permeation chromatography (GPC, 1260 Series, Agilent Technologies, New York, NY, USA). The glass 
transition temperature $\left(T_{g}\right)$ of polyurethane was measured using differential scanning calorimetry (DSC, Q2000, TA Instrument, New Castle, DE, USA) from -80 to $-20^{\circ} \mathrm{C}$ at a heating rate of $10{ }^{\circ} \mathrm{C} / \mathrm{min}$. The thermal stability of the polyurethane was examined using thermogravimetric analysis (TGA, Q500, TA Instrument, New Castle, DE, USA) in the range of 25 to $800^{\circ} \mathrm{C}$ at a heating rate of $10^{\circ} \mathrm{C} / \mathrm{min}$. Then, the tensile strengths of the cured epoxy compositions were measured with a universal testing machine (UTM, INSTRON 5982, Instron, USA) for test specimens processed to sizes of $150 \mathrm{~mm} \times 13 \mathrm{~mm} \times 3 \mathrm{~mm}$ based on the ASTM D 638 method. The flexural strengths of the cured compositions processed to sizes of $60 \mathrm{~mm} \times 25 \mathrm{~mm} \times 3 \mathrm{~mm}$ were tested by using the ASTM D 790M method. The tensile and flexural tests were repeated five times to obtain average values. The Izod impact strengths were measured using the ASTM D 256 method for cured compositions with sizes of $63.5 \mathrm{~mm} \times 12.7 \mathrm{~mm} \times 3 \mathrm{~mm}$ with a pendulum impact tester (HIT-2492, JJ-TEST, Chengde, China). The dynamic mechanical analysis (DMA, Q800, TA Instrument, New Castle, DE, USA) of the epoxy compositions was performed using a Q800 with test specimens measuring $60 \mathrm{~mm} \times 12 \mathrm{~mm} \times 3 \mathrm{~mm}$. The specimens were installed on the dual cantilever probe while the operating temperature increased at a heating rate of $5{ }^{\circ} \mathrm{C} / \mathrm{min}$ under a $1 \mathrm{~Hz}$ frequency to measure both the storage moduli and $\tan \delta$ values. Furthermore, the thermal stabilities of the cured epoxy compositions were measured using TGA (TGA, Q500, TA Instrument, New Castle DE. USA) in the range of 25 to $800{ }^{\circ} \mathrm{C}$ at a heating rate of $10^{\circ} \mathrm{C} / \mathrm{min}$.

\section{Results and Discussion}

\subsection{Characterization}

The structures of the prepared polyurethanes were analyzed with ${ }^{1} \mathrm{H}-\mathrm{NMR}$, ESI-MS, and elemental analysis. The proton peaks of secondary carbon (i) and tertiary carbon (h) formed by a ring opening reaction of the epoxy group were observed in the 4.05-4.32 (ppm) range, as shown in Figure 2.
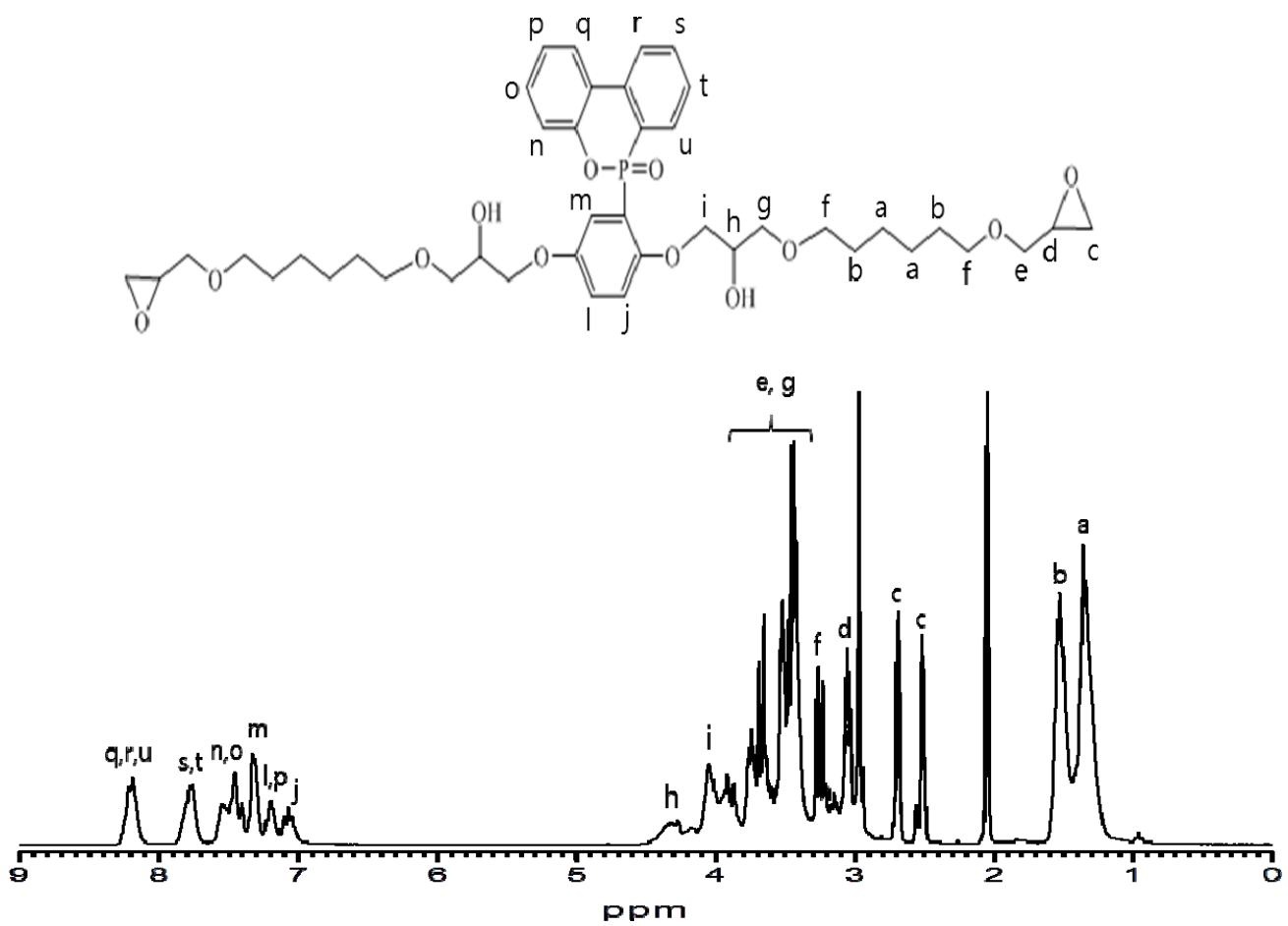

Figure 2. ${ }^{1} \mathrm{H}-\mathrm{NMR}$ spectrum of EP-DOPO.

${ }^{1} \mathrm{H}$ NMR $(300 \mathrm{MHz}$, Acetone): $\delta(\mathrm{ppm})=1.36(8 \mathrm{H}, m), 1.53(8 \mathrm{H}, m), 2.52,2.69(4 \mathrm{H}, d), 3.05(2 \mathrm{H}, m)$, 3.26 3.90 $(12 \mathrm{H}, m), 4.32(2 \mathrm{H}, m), 4.05(4 \mathrm{H}, d)$. EA calc'd for $\mathrm{C}_{42} \mathrm{H}_{57} \mathrm{O}_{12} \mathrm{P}: \mathrm{C}, 64.27 ; \mathrm{H}, 7.32 ; \mathrm{O}, 24.46 ; \mathrm{P}$, 3.95. found: $\mathrm{C}, 60.95 ; \mathrm{H}, 5.99 ; \mathrm{O}, 22.86$. LC-ESI-MS: found $785.3(\mathrm{M}+\mathrm{H})^{+}$, calc'd 784.3. 
Polyurethane was prepared by reacting polyol with IPDI followed by capping the terminal-NCO (isocyanate) group with a phenol $\mathrm{OH}$ group, as shown in Figure 3.

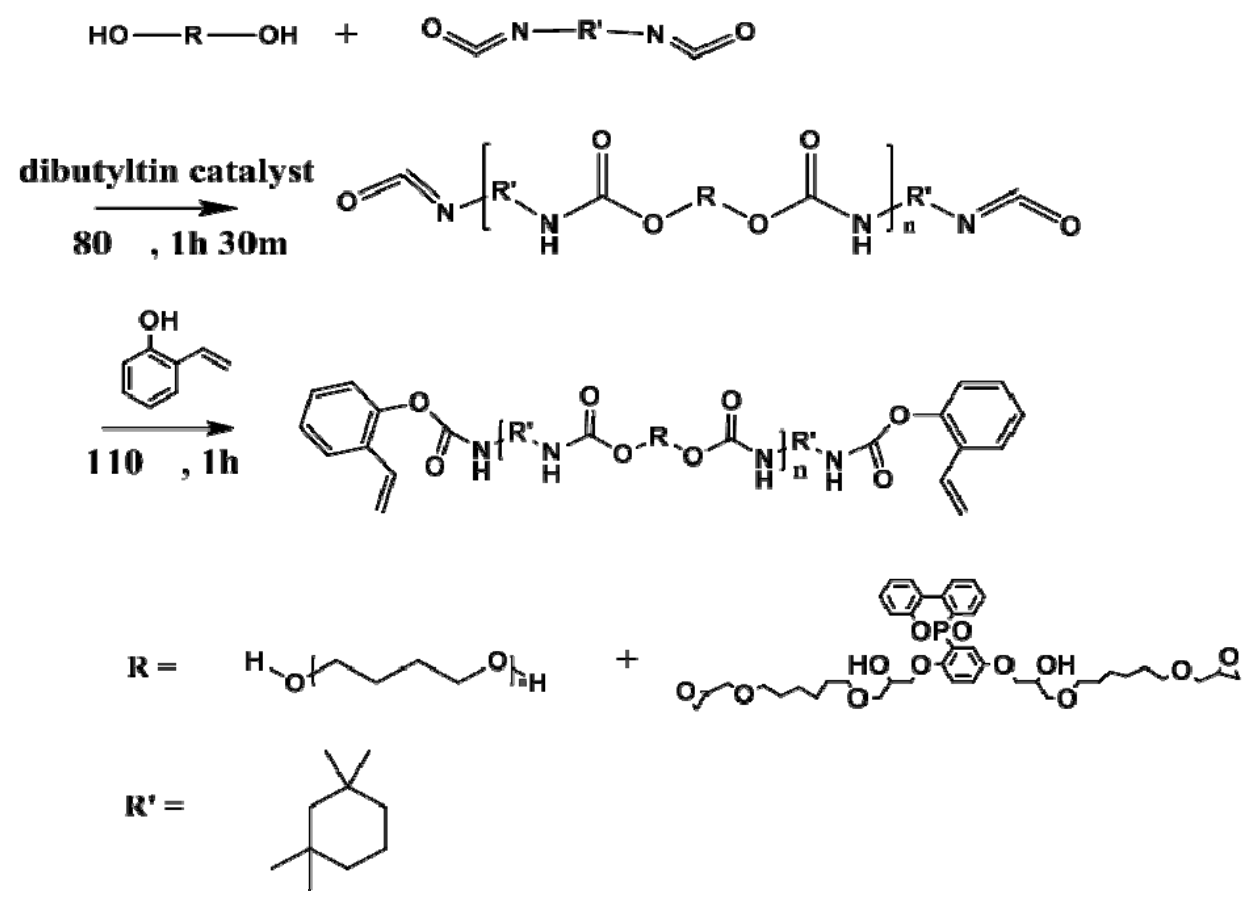

Figure 3. Reaction scheme for polyurethanes.

The molecular weights of the prepared polyurethanes were analyzed with GPC (Figure 4) and the molecular weights and dispersity data are shown in Table 1.

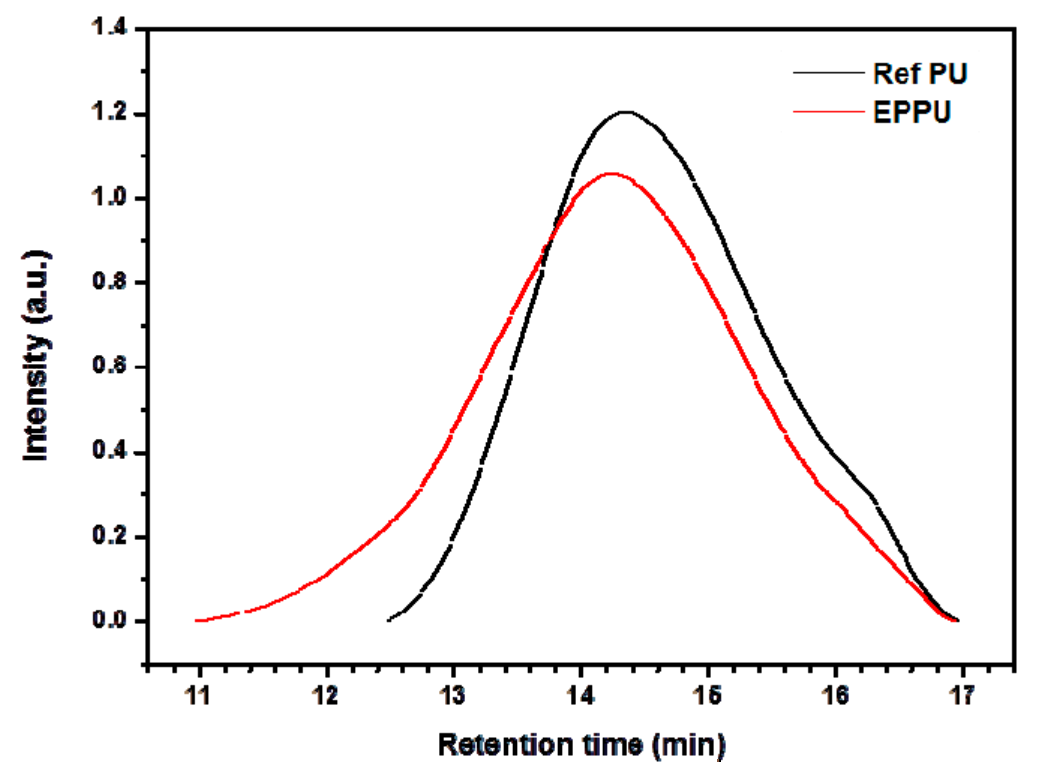

Figure 4. GPC data for polyurethanes, intensity (arbitrary unit) vs retention time (min)).

Table 1. Molecular weights of polyurethanes.

\begin{tabular}{cccc}
\hline & $\boldsymbol{M}_{\boldsymbol{n}}(\mathrm{g} / \mathrm{mol})$ & $\boldsymbol{M}_{\boldsymbol{w}}(\mathrm{g} / \mathrm{mol})$ & $\boldsymbol{D}$ \\
\hline Ref PU & 7556 & 13,158 & 1.74 \\
EPPU & 9338 & 21,112 & 2.26 \\
EPPU-2 & 3133 & 4143 & 1.32 \\
\hline
\end{tabular}


The prepared polyurethanes were analyzed with GPC to check whether two polyurethanes have a similar range of molecular weight. It turned out that both polyurethanes have a similar range of molecular weight: $9338 \mathrm{~g} / \mathrm{mol}$ for EPPU and $7556 \mathrm{~g} / \mathrm{mol}$ for Ref PU. However, EPPU-2 has a small molecular weight because it is synthesized by reacting small molecular weight of EP-DOPO with diisocyanate (Figure S1).

\subsection{Thermal Properties of Polyurethane}

\subsubsection{Differential Scanning Calorimetry}

Polyurethane composed of a hard segment from diisocyanate and soft segment from polyols had two glass transition temperatures due to the individual segments. The glass transition temperature of the soft segment was usually observed at low temperatures, below $0{ }^{\circ} \mathrm{C}$. The DSC data (Figure 5) shows the $T_{g}$ values of Ref PU and EPPU at -69 , and $-60{ }^{\circ} \mathrm{C}$, respectively. This suggests that EP-DOPO, which is more rigid than PTMG, causes the higher $T_{g}$ of the EPPU soft segment. For the same reason, $T_{g}$ of EPPU-2 synthesized by reacting EP-DOPO polyol with IPDI was $-8.8^{\circ} \mathrm{C}$ (Figure S2)

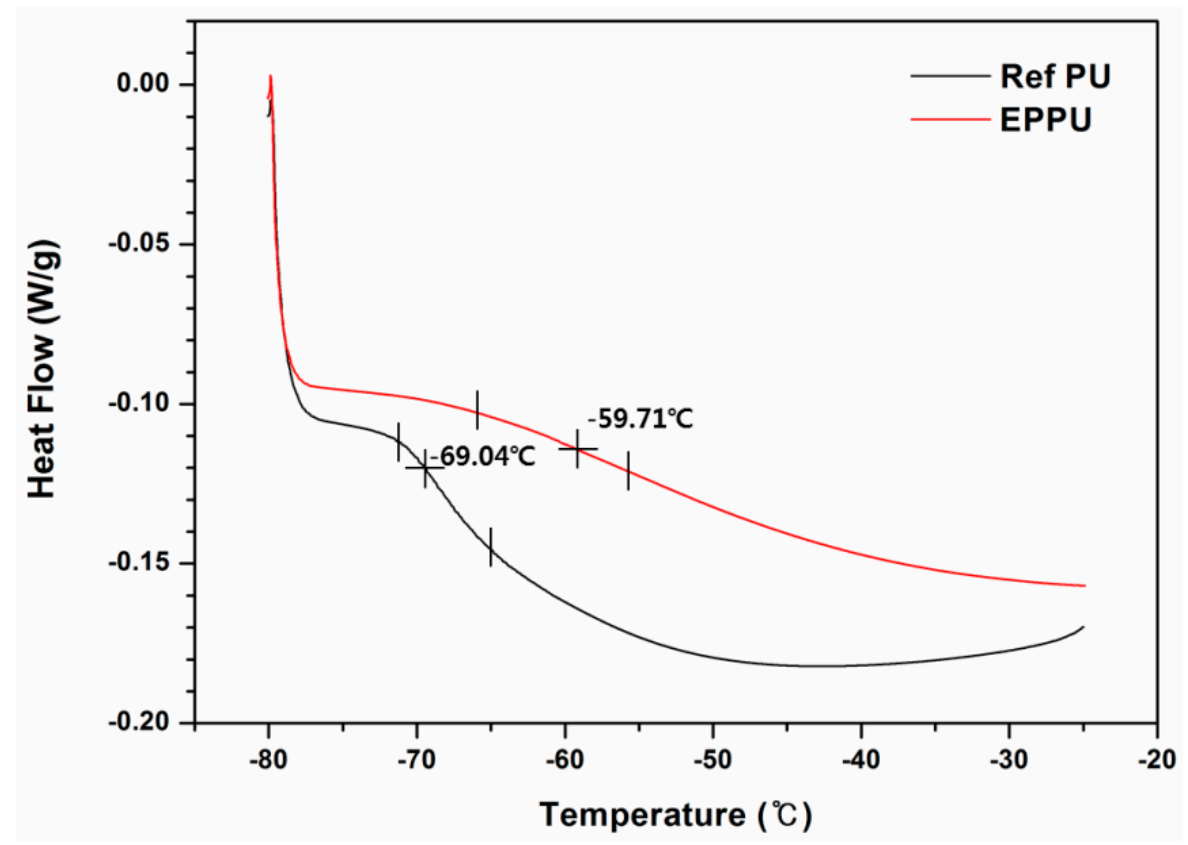

Figure 5. Differential scanning calorimetry (DSC) data for Ref PU and EPPU.

\subsubsection{Thermogravimetric Analysis}

Van Krevelen suggested that one way to reduce the burning of polymers is to add charcoal-forming additives like phosphor [16]. Lyon developed a method for measuring flame retardancy from polymers that produce charcoal with TGA [17]. The phosphor used in this study for flame retardancy is known to react with a combustible material during combustion and form a carbonized layer on the surface of the material. In addition, the phosphorous flame retardant produces phosphoric acid and polyphosphoric acid by pyrolysis, resulting in the formation of a $\mathrm{HPO}_{2}$ or $\mathrm{PO}$ radical that stabilizes the active $\mathrm{OH}$ or $\cdot \mathrm{H}$ radicals $[18,19]$. TGA analysis was carried out to evaluate the thermal stabilities of Ref PU and EPPU by comparing the pyrolysis temperatures at $5 \%$ and $20 \%$ weight loss ratios. Furthermore, flame retardancy was evaluated by measuring the total residual amount of material remaining after thermal decomposition related to the degree of formation of char. Plots of the weight reduction rate versus the temperature measured under a $\mathrm{N}_{2}$, or air atmosphere are displayed in Figures 6 and 7 , and the results are summarized in Tables 2 and 3. In Figure 6, EP-DOPO with a large amount of phosphorus showed a residual amount of $11.9 \%$ at over $400{ }^{\circ} \mathrm{C}$ under nitrogen gas. Ref PU without phosphorus showed a small residual amount of $0.2 \%$. However, EPPU and EPPU-2 have phosphorus 
in their structures, but their residual amounts were $1.2 \%$ and $3.0 \%$, respectively. The results of TGA analysis under an oxygen atmosphere show that the residual amount of EP-DOPO at temperatures over $400{ }^{\circ} \mathrm{C}$ was $28.2 \%$ (Figure 7), which is higher than that measured in the $\mathrm{N}_{2}$ atmosphere (Figure 6). In addition, the residual amount of EPPU and EPPU-2, which showed a small residual amount in the $\mathrm{N}_{2}$ atmosphere, increased to $13.9 \%$ and $16.8 \%$ in the oxygen atmosphere, respectively. It was confirmed that the flame-retardant effect of phosphorus in the air atmosphere was better than that in the nitrogen atmosphere. This result agrees with a previous report which showed that the residual amount increases as the phosphorus content increases [20]. The temperatures at which EPPU lost $5 \%$ and $20 \%$ of its initial weight were as high as 16 and $58^{\circ} \mathrm{C}$ compared to those of Ref PU, respectively. Since EPPU is rich in aromatic groups that improve heat resistance, the pyrolysis temperature of EPPU is higher than that of Ref PU. Furthermore, EPPU-2 having higher content of phosphorous than that of EPPU showed better thermal stability than EPPU. The high thermal stability of EPPU is useful in industrial applications, such as cables or wires.

Table 2. Thermal degradation temperatures of polyurethanes obtained with thermogravimetric analysis (TGA) $\left(\mathrm{N}_{2}\right)$.

\begin{tabular}{cccc}
\hline $\mathbf{N}_{\mathbf{2}}$ Atmosphere & $\begin{array}{c}\text { Temp. at } \mathbf{5} \% \text { Weight } \\
\text { Loss }\left({ }^{\circ} \mathbf{C}\right)\end{array}$ & $\begin{array}{c}\text { Temp. at } \mathbf{2 0} \% \text { Weight } \\
\text { Loss }\left({ }^{\circ} \mathbf{C}\right)\end{array}$ & Char at $\mathbf{4 5 0}{ }^{\circ} \mathbf{C}(\mathbf{\%})$ \\
\hline EP-DOPO & 226 & 341 & 11.9 \\
REF PU & 152 & 230 & 0.2 \\
EPPU & 168 & 288 & 1.2 \\
EPPU-2 & 207 & 341 & 3.0 \\
\hline
\end{tabular}

Table 3. Thermal degradation temperature of polyurethanes obtained with TGA (air).

\begin{tabular}{cccc}
\hline Air Atmosphere & $\begin{array}{c}\text { Temp at } \mathbf{5 \%} \text { Weight Loss } \\
\mathbf{(} \mathbf{C})\end{array}$ & $\begin{array}{c}\text { Temp at } \mathbf{2 0} \% \text { Weight Loss } \\
\mathbf{(} \mathbf{C})\end{array}$ & Char at $\mathbf{4 5 0}{ }^{\circ} \mathbf{C}(\mathbf{\%})$ \\
\hline EP-DOPO & 242 & 337 & 28.2 \\
REF PU & 157 & 248 & 6.5 \\
EPPU & 164 & 300 & 13.9 \\
EPPU-2 & 214 & 328 & 16.8 \\
\hline
\end{tabular}

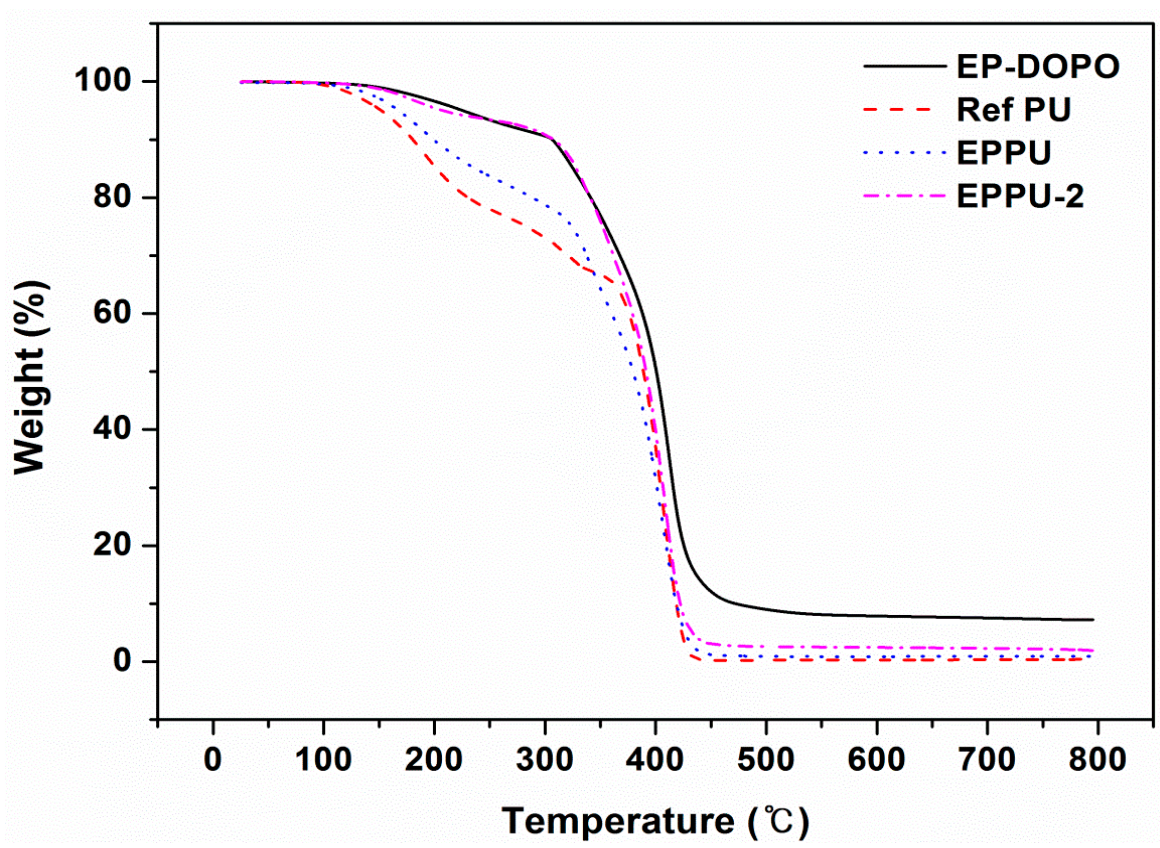

Figure 6. Thermogravimetric analysis (TGA) data for Ref PU and EPPU in $\mathrm{N}_{2}$ DOPO: 10-(2,5-dihydroxyphenyl)-10H-9-oxa-10-phospha-phenanthrene-10-oxide. 


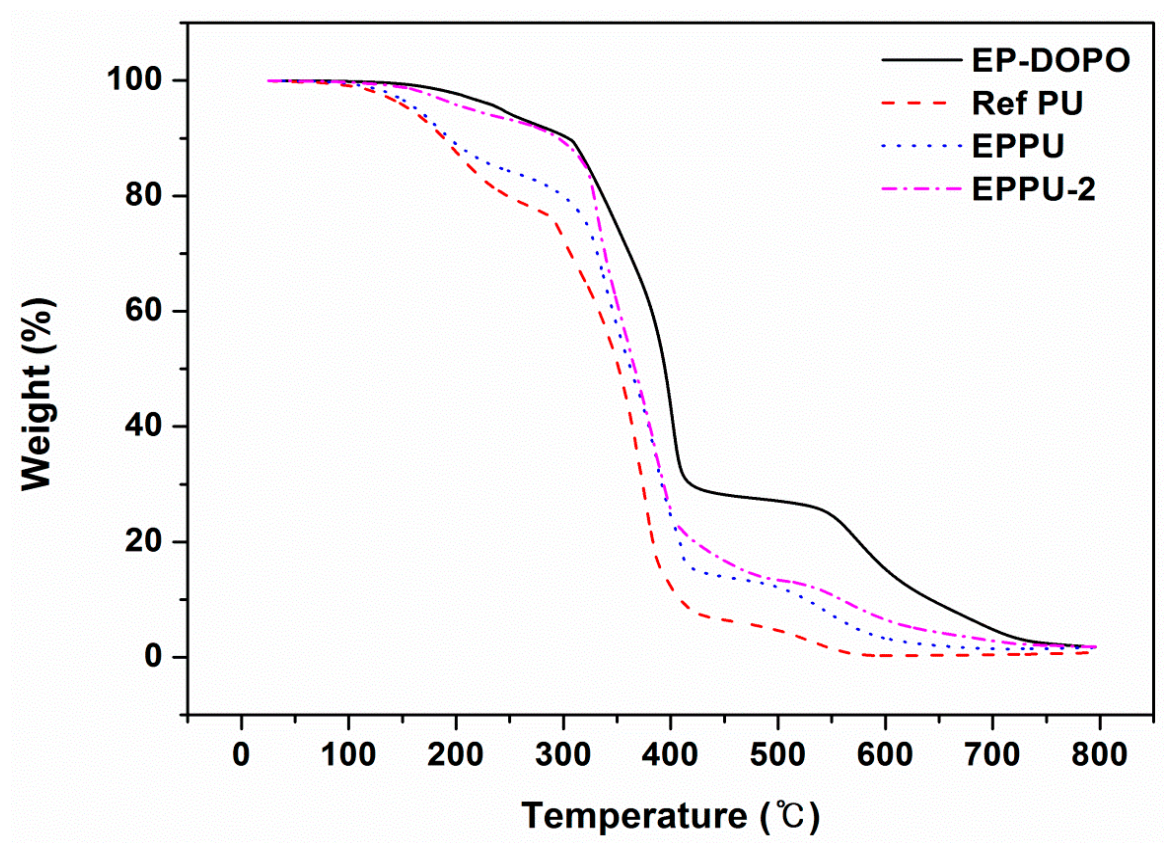

Figure 7. TGA data for Ref PU and EPPU in air.

\subsection{Characterization of Epoxy Compositions with Polyurethanes}

In addition, the properties of the prepared polyurethanes as a toughener were studied by adding them to epoxy compositions composed of an epoxy resin and a curing agent: dicy. The epoxy compositions include various amounts of PU, except for EPPU-2 because it has a high viscosity; it was cured as described previously to prepare the test specimens for the measurements of the mechanical and thermal properties. Figure 8a shows that epoxy compositions with synthetic EPPU had higher tensile strengths than those of the epoxy compositions with Ref PU. Furthermore, epoxy compositions containing EPPU have higher flexural strength than epoxy compositions containing Ref PU (Figure 8b). This indicates that the rigid EPPU in the epoxy compositions compensated for the flexibility of the overall PU and enhanced the mechanical strength. In addition, the impact resistance of the epoxy binder with $10 \mathrm{phr}$ of EPPU increased by $17 \%$ compared to that of neat epoxy (Figure $8 \mathrm{c}$ ). However, when more than $10 \mathrm{phr}$ of EPPU was included in the epoxy compositions, the impact resistance became lower than that of the epoxy with Ref PU due to the increased rigidity from aromatic groups in EPPU [21].

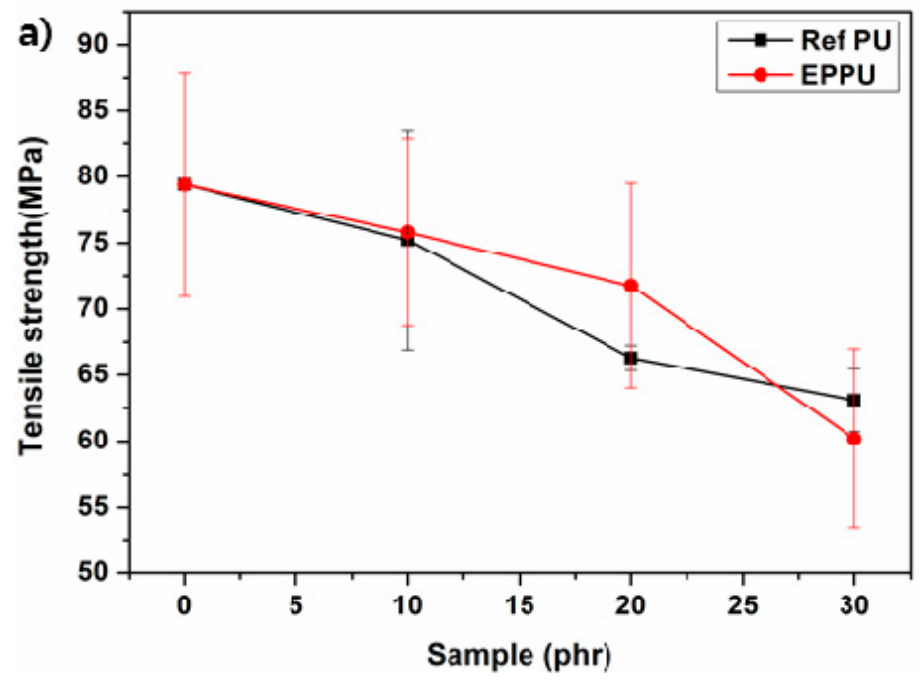

Figure 8. Cont. 

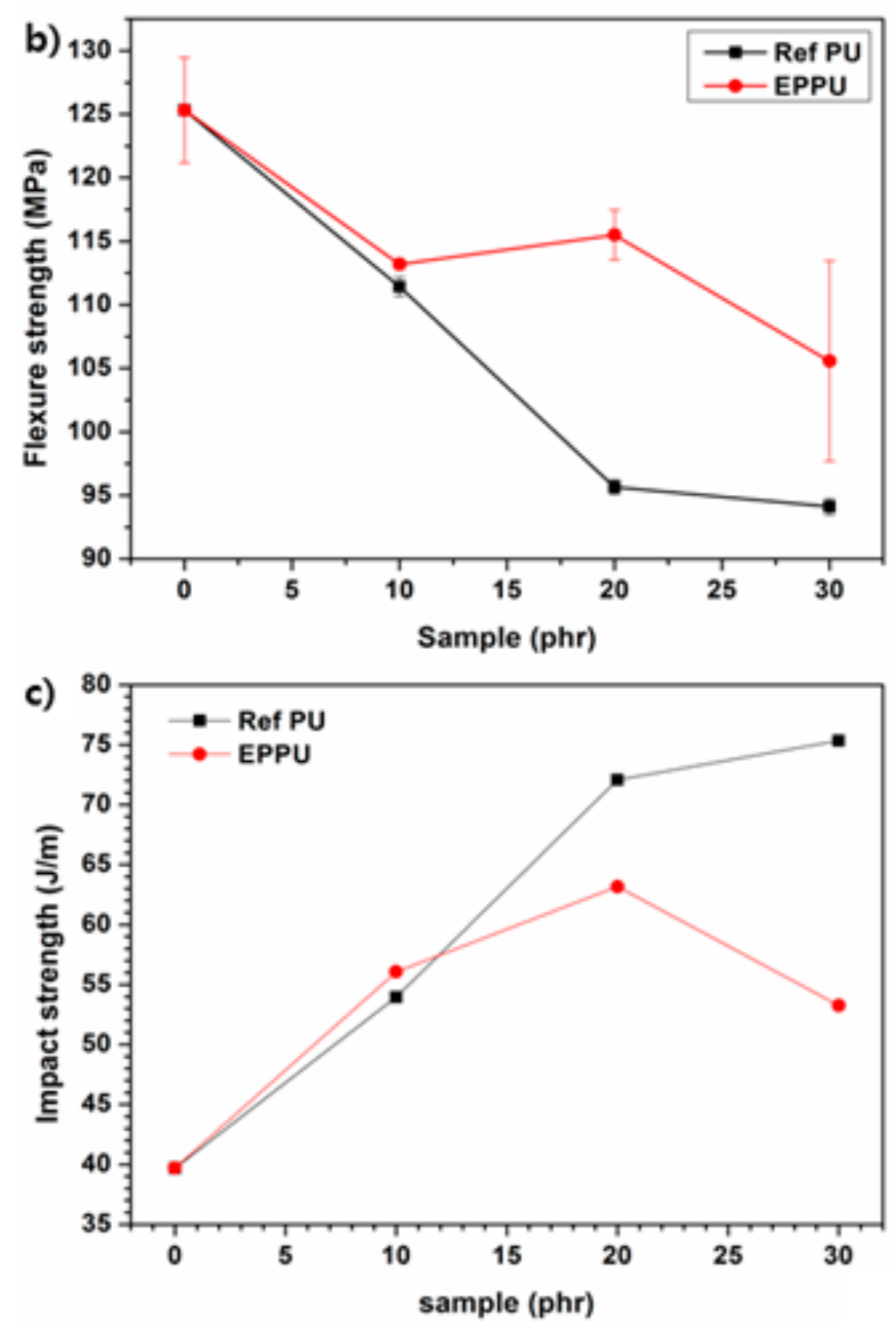

Figure 8. Mechanical strength data for epoxy composites including various amounts of Ref PU or EPPU: (a) tensile strength $\sim(\mathbf{b})$ flexural strength and (c) impact resistance. phr: parts per hundred resin.

The viscoelastic properties of each epoxy composition were measured using DMA. The storage modulus and $\tan \delta$ curves are displayed in Figure $9 \mathrm{a}, \mathrm{b}$, and the calculated crosslink density values are shown in Table 4 . The storage modulus $\left(E^{\prime}\right)$ of neat epoxy exhibited the highest value, while the $E^{\prime}$ of the epoxy compositions decreased as the amount of PU in the epoxy matrix increased. Meanwhile, the storage moduli of the EPPU epoxy compositions were higher than those of the Ref PU epoxy compositions. The high crosslink density of the EPPU epoxy matrix can cause this, because the diglycidyl ethers of EPPU can form a polymer network structure with an amine hardener [22]. To calculate the crosslink density of each epoxy composition in the rubbery plateau region in the range of $150-250{ }^{\circ} \mathrm{C}$, the following equation was used:

$$
\mathrm{V}_{c}=\frac{E^{\prime}}{3 R T}
$$

where $V_{c}$ is the crosslink density, $E^{\prime}$ is the tensile storage modulus in the rubbery plateau, $T$ is the temperature in $\mathrm{K}$ corresponding to the storage modulus value, and $R$ is the gas constant. The calculated values for the EPPU epoxy compositions were higher than those of the Ref PU epoxy binder with the same amount of polyurethanes. These results correspond to the storage modulus values listed in Table 4. However, the $V_{c}$ values of the epoxy compositions with EPPU also decreased as the content of polyurethane increased. This was caused by the decreased amount of epoxy resin forming network 
polymers [23,24]. In Figure 9b, one can see that the curves in the tan $\delta$ plot of the epoxy compositions tend to decrease owing to the increase of the flexible segment of the polyurethane, giving rise to chain motion. Specifically, it is obvious that epoxy binders containing EPPU have higher glass transition temperatures than those of the epoxy compositions with Ref PUs because both phenanthrene and the benzene group of EPPU function as hard segments that restrain the chain motion of PU in the polymer matrix. In addition, parameters such as the aromatic density can change the thermal properties of the polymer, increasing $T_{g}$ or improving the degradation characteristics [25].
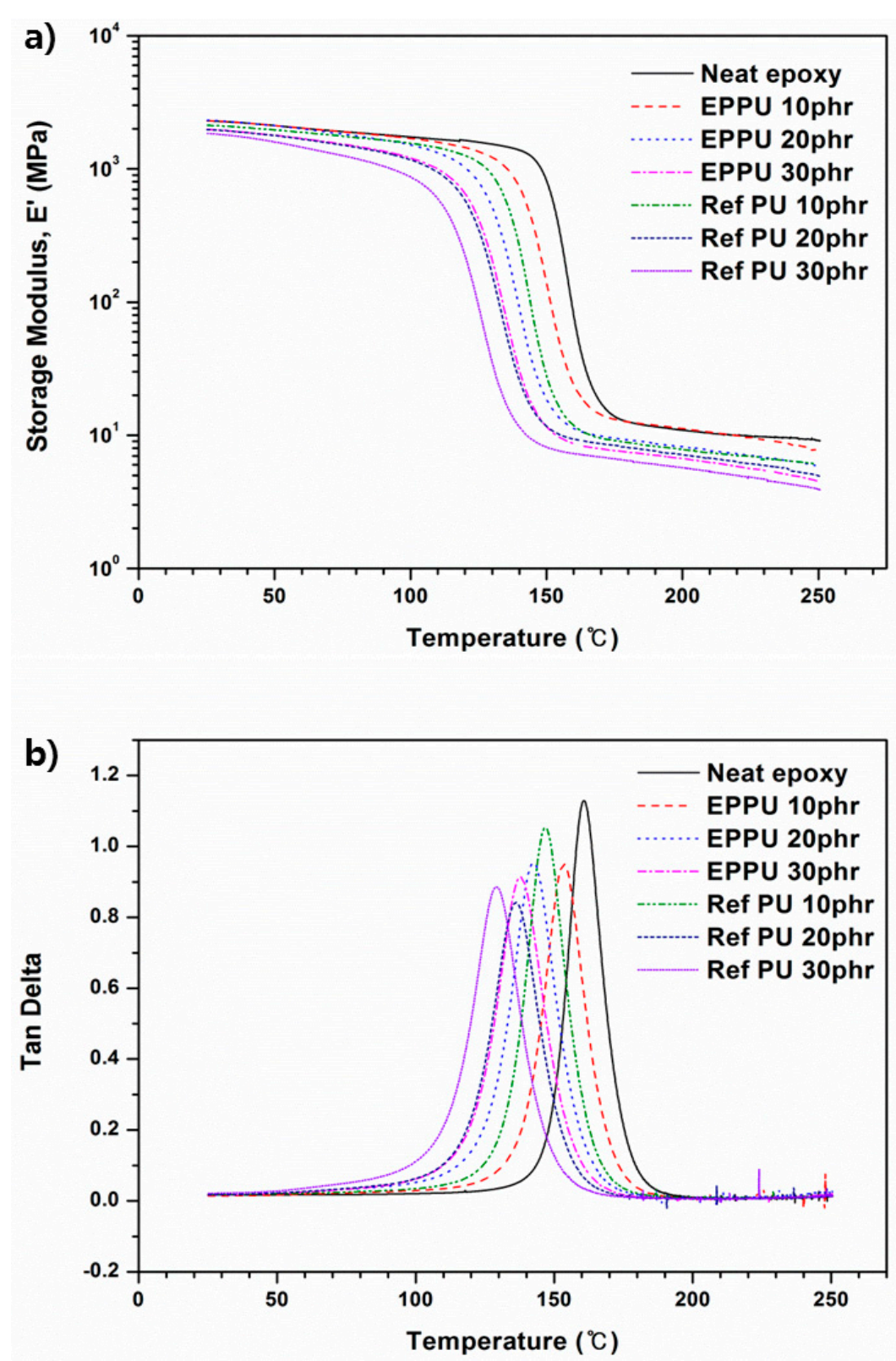

Figure 9. (a) Storage moduli of epoxy compositions and (b) $\tan \delta$ values.

The thermal stabilities of the epoxy compositions containing PUs were measured using TGA and observing the weight loss as a function of temperature (Figure 10). The thermal data are collected in Table 5 . For a weight loss of $5 \%$, the thermal degradation temperature $\left(T_{5 \%}\right)$ decreased proportionally to the content of polyurethane in the epoxy binder, indicating reduced thermal stability. Based on the values at $T_{5 \%}$, and $T_{10 \%}$, the epoxy with $10 \mathrm{phr}$ of Ref PU had the highest temperature. This is thought to be related to the morphology of PU in the cured epoxy matrix, as shown in Figure 11, which shows 
the scanning electron microscopy (SEM) images of each epoxy sample. Figure $11 \mathrm{~b} 1$ shows a large amount of phase-separated PUs in the epoxy binder with $10 \mathrm{phr}$ of Ref PU. The thermal degradation of the volatile segments of the phase-separated PUs was delayed by the surrounding epoxy matrix and resulted in the highest thermal degradation temperature. Neat epoxy and epoxy compositions with PUs exhibited similar degradation temperatures within a $\pm 2 \%$ range. This indicates that the content of the flame-retardant phosphor was too low to provide flame retardancy.

Surface images of neat resin (Figure 11a1,a2) showed mainly smooth surfaces with partial wavy patterns. However, an epoxy composition with $10 \mathrm{phr}$ of Ref PU (Figure 11b1) or EPPU (Figure 11cl) showed numerous holes resulting from impact-detached PUs. Other images, including those with $>10$ phr of polyurethanes, did not show phase-separated polyurethanes but had rough surfaces as the PU content increased. This suggests that the high polyurethane content in the epoxy matrix promoted flexibility, compensating for the embrittlement of the cured epoxy product, but also lowered the tensile and flexural strengths of the epoxy.

Table 4. Storage moduli and $V_{c}$ of epoxy compositions containing PUs. phr: parts per hundred resin; DMA: dynamic mechanical analysis.

\begin{tabular}{cccccccc}
\hline & $\begin{array}{c}\text { Neat } \\
\text { Epoxy }\end{array}$ & $\begin{array}{c}\text { EPPU } \\
\mathbf{1 0} \mathbf{~ p h r}\end{array}$ & $\begin{array}{c}\text { EPPU } \\
\mathbf{2 0} \mathbf{~ p h r}\end{array}$ & $\begin{array}{c}\text { EPPU } \\
\mathbf{3 0} \mathbf{~ p h r}\end{array}$ & $\begin{array}{c}\text { Ref PU } \\
\mathbf{1 0} \mathbf{~ p h r}\end{array}$ & $\begin{array}{c}\text { Ref PU } \\
\mathbf{2 0} \mathbf{p h r}\end{array}$ & $\begin{array}{c}\text { Ref PU } \\
\mathbf{3 0} \mathbf{~ p h r}\end{array}$ \\
\hline$R(\mathrm{~L} \cdot \mathrm{MPa} \cdot \mathrm{K}-1 \cdot \mathrm{mol}-1)$ & & & & 0.008314 & & & \\
Storage modulus, $E^{\prime}\left(\mathrm{MPa}\right.$ at $\left.180^{\circ} \mathrm{C}\right)$ & 1.1 & 1.1 & 0.965 & 0.873 & 0.946 & 0.908 & 0.811 \\
$T_{\mathrm{g}}\left({ }^{\circ} \mathrm{C}\right.$, with $\left.\mathrm{DMA}\right)$ & 160.8 & 153.6 & 142.8 & 138.2 & 146.8 & 136.7 & 129.4 \\
$V_{\mathrm{c}}(\mathrm{mol} / \mathrm{L})$ & 0.097 & 0.097 & 0.085 & 0.077 & 0.084 & 0.080 & 0.072 \\
\hline
\end{tabular}

Table 5. Thermogravimetric analysis data at $T_{5 \%}$ and $T_{10 \%}$ and remaining contents.

\begin{tabular}{cccccccc}
\hline & $\begin{array}{c}\text { Neat } \\
\text { Epoxy }\end{array}$ & $\begin{array}{c}\text { Ref PU } \\
\mathbf{1 0} \mathbf{~ p h r}\end{array}$ & $\begin{array}{c}\text { Ref PU } \\
\mathbf{2 0} \mathbf{~ p h r}\end{array}$ & $\begin{array}{c}\text { Ref PU } \\
\mathbf{3 0} \mathbf{~ p h r}\end{array}$ & $\begin{array}{c}\text { EPPU } \\
\mathbf{1 0} \mathbf{~ p h r}\end{array}$ & $\begin{array}{c}\text { EPPU } \\
\mathbf{2 0} \mathbf{~ p h r}\end{array}$ & $\begin{array}{c}\text { EPPU } \\
\mathbf{3 0} \mathbf{~ p h r}\end{array}$ \\
\hline$T_{5 \%}$ & 327.5 & 334.2 & 323.5 & 323.4 & 325.2 & 323.2 & 321.7 \\
$T_{10 \%}$ & 346.6 & 353.5 & 346.1 & 347.2 & 345.8 & 345 & 345.4 \\
Char at $600{ }^{\circ} \mathrm{C}(\%)$ & 11.4 & 12.2 & 8.9 & 8.1 & 10.2 & 9.4 & 9.0 \\
\hline
\end{tabular}

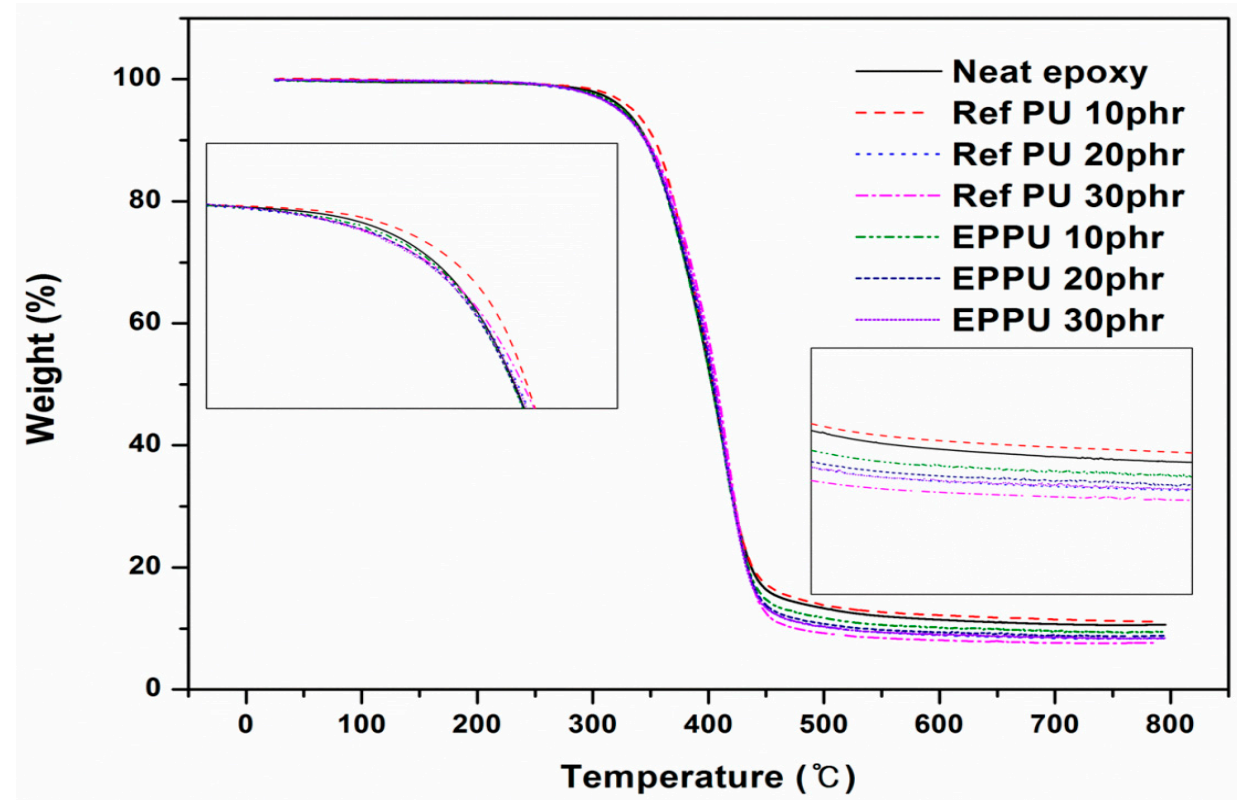

Figure 10. TGA curves for epoxy compositions including PUs. 

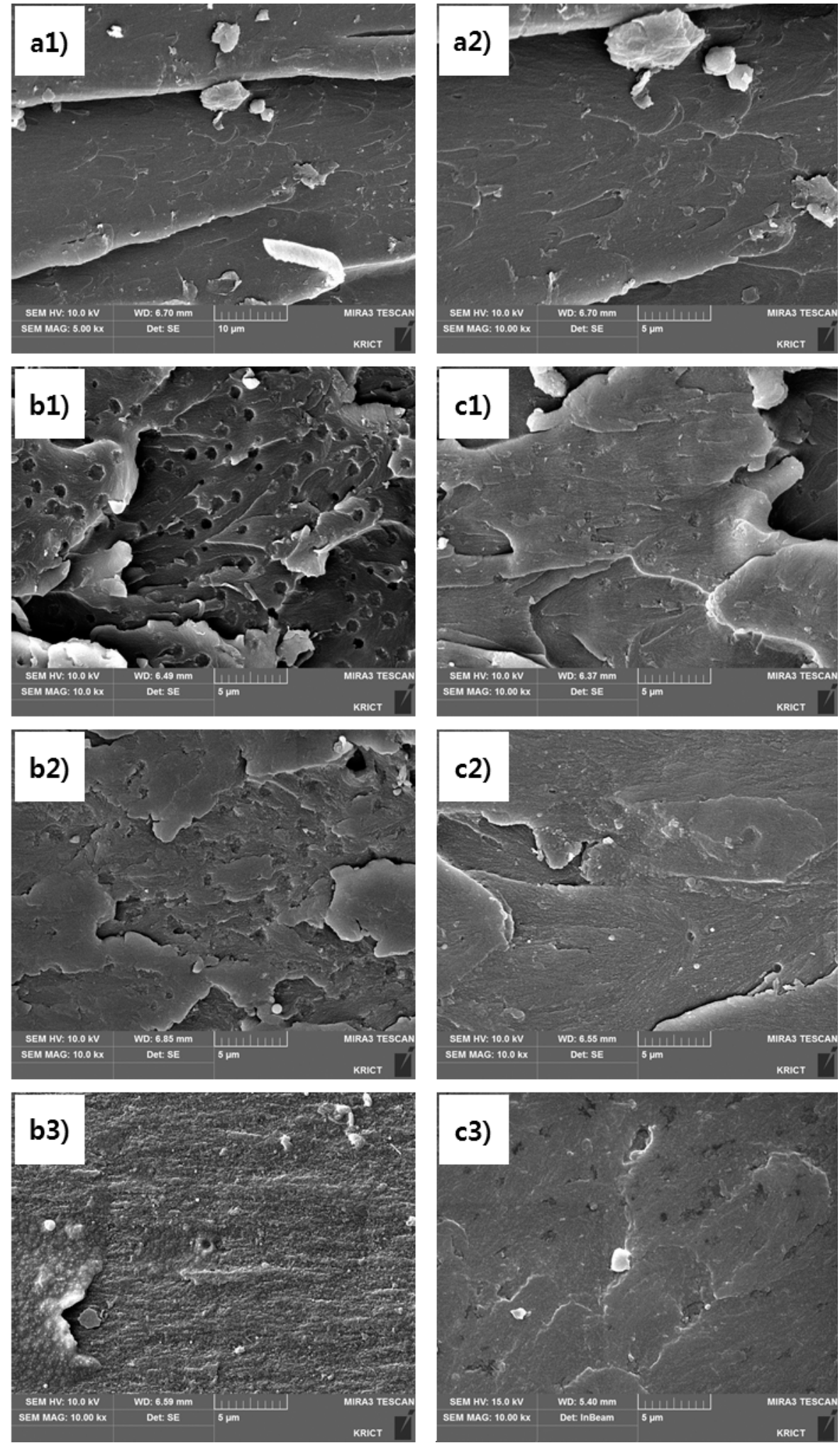

Figure 11. Scanning electron microscopy (SEM) images of epoxy compositions containing Ref PU or EPPU: (a1) neat epoxy at 5000 $\times$ magnification, (a2) neat epoxy at 10,000 $\times$ magnification; (b1-b3) epoxy compositions with 10, 20, and 30 phr Ref PU; (c1-c3) epoxy compositions with 10, 20, and 30 phr EPPU. 


\section{Conclusions}

In this study, a flame-retardant polyol (EP-DOPO) was prepared and characterized with ${ }^{1} \mathrm{H}-\mathrm{NMR}$, electron spray ionization mass spectrometry (ESI-MS), and elemental analysis. In addition, flame retardant polyurethanes (EPPU, and EPPU-2) were prepared by reacting the blend of EP-DOPO and PolyTHF polyol with IPDI. The physical properties of the EPPUs were compared with polyurethanes composed of PolyTHF and IPDI (Ref PU). DSC data showed that EPPU, having a rigid aromatic group, has the disadvantage of having a higher $T_{\mathrm{g}}$, due to its soft segment, compared to that of Ref PU. However, EPPU exhibited a higher thermal degradation temperature than Ref PU, as revealed by TGA. Therefore, these results suggest that EPPU itself can be useful for industrial applications requiring high thermal stability, such as wires and cables.

Furthermore, the effect of polyurethane in the epoxy binder as a toughener was investigated in terms of mechanical and thermal properties. The tensile strengths of the epoxy compositions with EPPU and Ref-PU were similar, but the EPPU-epoxy compositions had higher flexural strengths than the Ref PU-epoxy compositions, which is beneficial for preparing high-performance epoxy composites. Moreover, EPPU-epoxy compositions exhibited higher impact resistance than neat epoxy, though epoxy compositions containing 20 and $30 \mathrm{phr}$ had lower values than those of epoxy compositions with Ref PU.

Furthermore, the viscoelastic properties of the epoxy compositions with various amounts of EPPU were analyzed using DMA. According to the results, the epoxy polymer with $10 \mathrm{phr}$ of EPPU has higher $\tan \delta$ value than that of the cured epoxy with $10 \mathrm{phr}$ of Ref PU. Therefore, EPPU is useful for increasing the glass transition temperature $\left(T_{g}\right)$ of the polymer. Moreover, the calculated crosslink density values of the compositions based on the DMA results were also found to increase proportionally to the values of the storage modulus.

Supplementary Materials: The following are available online at http://www.mdpi.com/2076-3417/8/9/1587/s1, Figure S1: GPC data of EPPU-2, intensity vs retention time (min), Figure S2: DSC data for EPPU-2.

Author Contributions: J.H.K., and T.K. carried out experiments. W.L., and H.-G.K. analyzed the data. B.S. designed the experiment. C.-S.L., and I.W.C. wrote the paper.

Funding: This research was supported by the Korea Research Institute of Chemical Technology (No. SI1809), and by the Technology Innovation Program (10063520) funded by the Ministry of Trade, Industry \& Energy (MOTIE, Korea).

Conflicts of Interest: The authors declare no conflict of interest.

\section{References}

1. Lei, W.Q.; Fang, C.Q.; Zhou, X.; Cheng, Y.L.; Yang, R.; Liu, D.H. Morphology and thermal properties of polyurethane elastomer based on representative structural chain extenders. Thermochim. Acta 2017, 653, 116-125. [CrossRef]

2. Russo, P.; Acierno, D.; Marletta, G.; Destri, G.L. Tensile properties, thermal and morphological analysis of thermoplastic polyurethane films reinforced with multiwalled carbon nanotubes. Eur. Polym. J. 2013, 49, 3155-3164. [CrossRef]

3. Levchik, S.V.; Weil, E.D. Thermal decomposition, combustion and fire-retardancy of polyurethanes-A review of the recent literature. Polym. Int. 2004, 53, 1585-1610. [CrossRef]

4. Chattopadhyay, D.K.; Webster, D.C. Thermal stability and flame retardancy of polyurethanes. Prog. Polym. Sci. 2009, 34, 1068-1133. [CrossRef]

5. Zatorski, W.; Brzozowski, Z.K.; Kolbrecki, A. New developments in chemical modification of fire-safe rigid polyurethane foams. Polym. Degrad. Stab. 2008, 93, 2071-2076. [CrossRef]

6. Thirumal, M.; Singha, N.K.; Khastgir, D.; Manjunath, B.S.; Naik, Y.P. Halogen-free flame-retardant rigid polyurethane foams: Effect of alumina trihydrate and triphenylphosphate on the properties of polyurethane foams. J. Appl. Polym. Sci. 2010, 116, 2260-2268. [CrossRef]

7. Patel, R.H.; Patel, K.S. Synthesis and characterization of flame retardant hyperbranched polyurethanes for nano-composite and nano-coating applications. Prog. Org. Coat. 2015, 88, 283-292. [CrossRef] 
8. Patel, R.H.; Shah, M.D.; Patel, H.B. Synthesis and Characterization of Structurally Modified Polyurethanes Based on Castor Oil and Phosphorus-Containing Polyol for Flame-Retardant Coatings. Int. J. Polym. Anal. Charact. 2011, 16, 107-117. [CrossRef]

9. Zhang, B.L.; Tang, G.L.; Shi, K.Y.; You, Y.C.; Du, Z.J.; Yang, J.F.; Huang, J.A. Study on properties of epoxy resin toughened by functionalized polymer containing rigid, rod-like moiety. Eur. Polym. J. 2000, 36, 205-213. [CrossRef]

10. Thomas, R.; Durix, S.; Sinturel, C.; Omonov, T.; Goossens, S.; Groeninckx, G.; Moldenaers, P.; Thomas, S. Cure kinetics, morphology and miscibility of modified DGEBA-based epoxy resin-effects of a liquid rubber inclusion. Polymer 2007, 48, 1695-1710. [CrossRef]

11. Liu, Y.; Zhang, W.D.; Zhou, H.W. Mechanical properties of epoxy resin/hydroxyl-terminated polyester blends: effect of two-phase structure. Polym. Int. 2005, 54, 1408-1415. [CrossRef]

12. Iijima, T.; Sugizaki, A.; Fukuda, W.; Tomoi, M. Modification of Aromatic Diamine-cured Epoxy Resins by Poly(oxymethylene) or Hybrid Modifiers Containing Poly (oxymethylene). Polym. Int. 1997, 44, 125-133. [CrossRef]

13. Zou, Z.P.; Liu, X.B.; Wu, Y.P.; Tang, B.; Chen, M.; Zhao, X.L. Hyperbranched polyurethane as a highly efficient toughener in epoxy thermosets with reaction-induced microphase separation. RSC Adv. 2016, 6, 18060-18070. [CrossRef]

14. Reghunadhan, A.; Datta, J.; Kalarikkal, N.; Thomas, S. Development of nanoscale morphology and role of viscoelastic phase separation on the properties of epoxy/recycled polyurethane blends. Polymer 2017, 117, 96-106. [CrossRef]

15. Mulhaupt, R.; Powell, J.H.; Adderley, C.S.; Rufenacht, W. Phenol-Terminated Polyurethane or Polyuria (Urethane) with Epoxy Resin. U. S. Patent 5,278,257, 11 January 1994.

16. Krevelen, D.W.V. Some basic aspects of flame resistance of polymeric materials. Polymer 1975, 16, 615-620. [CrossRef]

17. Lyon, R.E. Pyrolysis kinetics of char-forming polymers. Polym. Degrad. Stab. 1998, 61, 201-210. [CrossRef]

18. Schartel, B. Phosphorus-based flame retardancy mechanisms-old hator a starting point for future development. Materials 2010, 3, 4710-4745. [CrossRef] [PubMed]

19. Van Der Veen, I.; De Boer, J. Phosphorus flame retardants: Properties, production, environmental occurrence, toxicity and analysis. Chemosphere 2012, 88, 1119-1153. [CrossRef] [PubMed]

20. Mequanint, K.; Sanderson, R.; Pasch, H. Thermogravimetric study of phosphated polyurethane ionomers. Polym. Degrad. Stab. 2002, 77, 121-128. [CrossRef]

21. Saralegi, A.; Rueda, L.; Fernández-d'Arlas, B.; Mondragon, I.; Eceiza, A.; Corcuera, M.A. Thermoplastic polyurethanes from renewable resources: effect of soft segment chemical structure and molecular weight on morphology and final properties. Polym. Int. 2013, 62, 106-115. [CrossRef]

22. Yu, W.W.; Zhang, D.Z.; Du, M.; Qiang, Z. Role of graded length side chains up to 18 carbons in length on the damping behavior of polyurethane/epoxy interpenetrating polymer networks. Eur. Polym. J. 2013, 49, 1731-1741. [CrossRef]

23. Zheng, N.; Fang, G.Q.; Cao, Z.L.; Zhao, Q.; Xie, T. High strain epoxy shape memory polymer. Polym. Chem. 2015, 6, 3046-3053. [CrossRef]

24. Leonardi, A.B.; Fasce, L.A.; Zucchi, I.A.; Hoppe, C.E.; Soule, E.R.; Perez, C.J.; Williams, R.J.J. Shape Memory Epoxies Based on Networks with Chemical and Physical Crosslinks. Eur. Polym. J. 2011, 47, 362-369. [CrossRef]

25. Fache, M.; Camille, M.; Boutevin, B.; Caillol, S. Amine hardeners and epoxy crosslinker from aromatic renewable resources. Eur. Polym. J. 2015, 73, 344-362. [CrossRef]

(C) 2018 by the authors. Licensee MDPI, Basel, Switzerland. This article is an open access article distributed under the terms and conditions of the Creative Commons Attribution (CC BY) license (http:/ / creativecommons.org/licenses/by/4.0/). 